Supporting Information for:

\title{
Development of Real-time Analysis System of Selenium lon in Solutions by using Microextraction and Fluorescence
}

\section{Microscopy}

Aileen Brandt, and Takehiko Tsukahara ${ }^{\dagger}$

Laboratory for Advanced Nuclear Energy, Institute of Innovative Research, Tokyo

Institute of Technology, 2-12-1-N1-6, Ookayama, Meguro, Tokyo 152-8550, Japan

$\dagger$ To whom correspondence should be addressed:

Takehiko Tsukahara: ptsuka@lane.iir.titech.ac.jp 


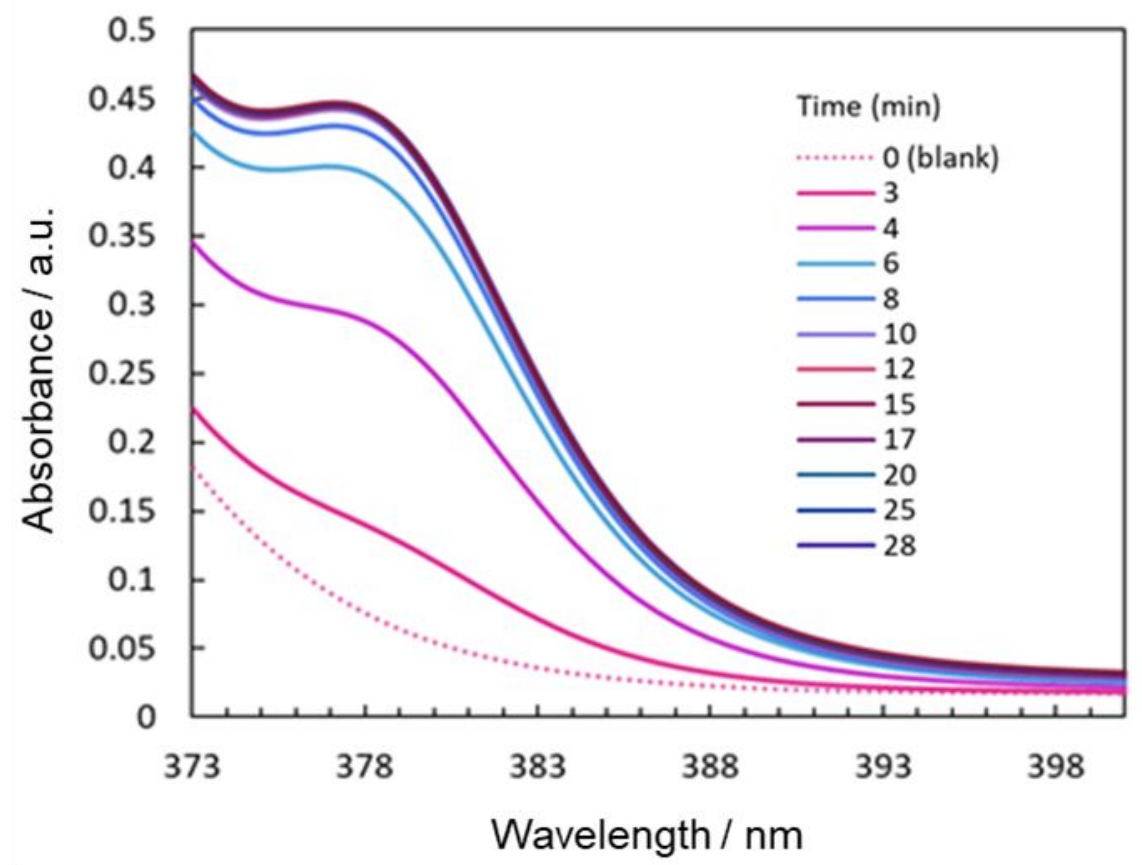

Figure S2-S1. UV-Vis absorption spectra of aqueous solution of BPS under the conditions of $\mathrm{pH} 1.5,50^{\circ} \mathrm{C}$, and $[\mathrm{DAN}] /[\mathrm{Se}(\mathrm{IV})]$ of 208 with proceeding reaction time. 


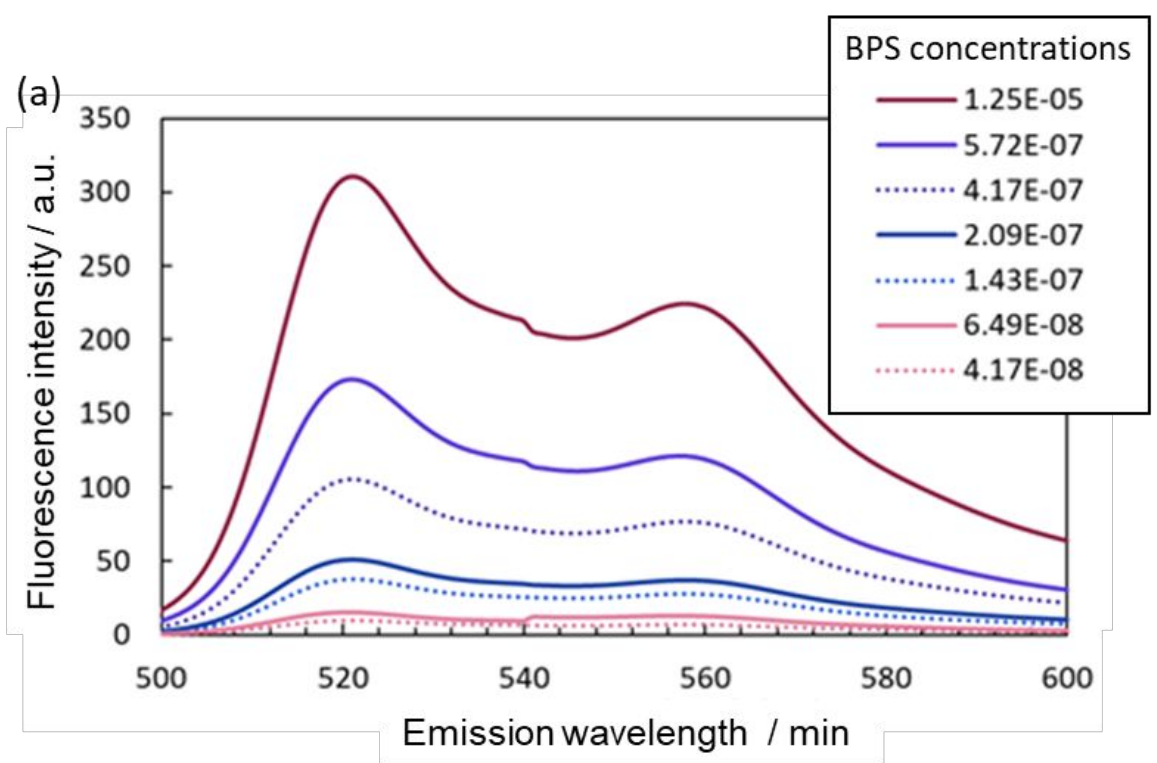

(b) $\quad E m .520 \mathrm{~nm}(E x .378 \mathrm{~nm})$

(c)

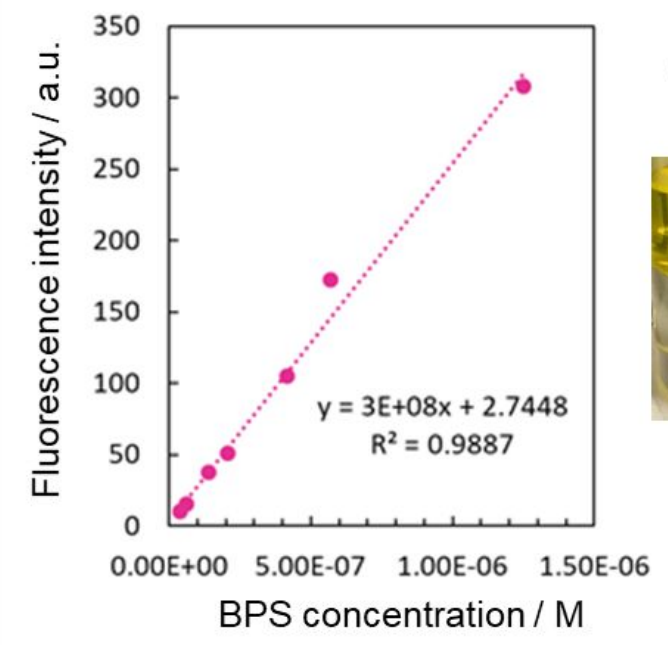

Optical Fluorescence image image

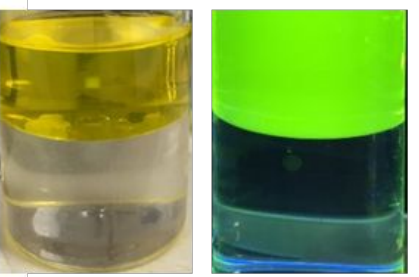

BPS

in Qrg.

Aq.

Figure S3-S2. (a) Fluorescence emission spectra of BPS in cyclohexane solutions at an excitation wavelength of $378 \mathrm{~nm}$. (b) A calibration curve of the fluorescence intensities vs. BPS concentrations. (c) Optical and fluorescence images of BPS obtained after bulk-scale extraction. The fluorescence image was observed by UV light irradiation (UV-lamp LUV-16, 365nm, As one). 

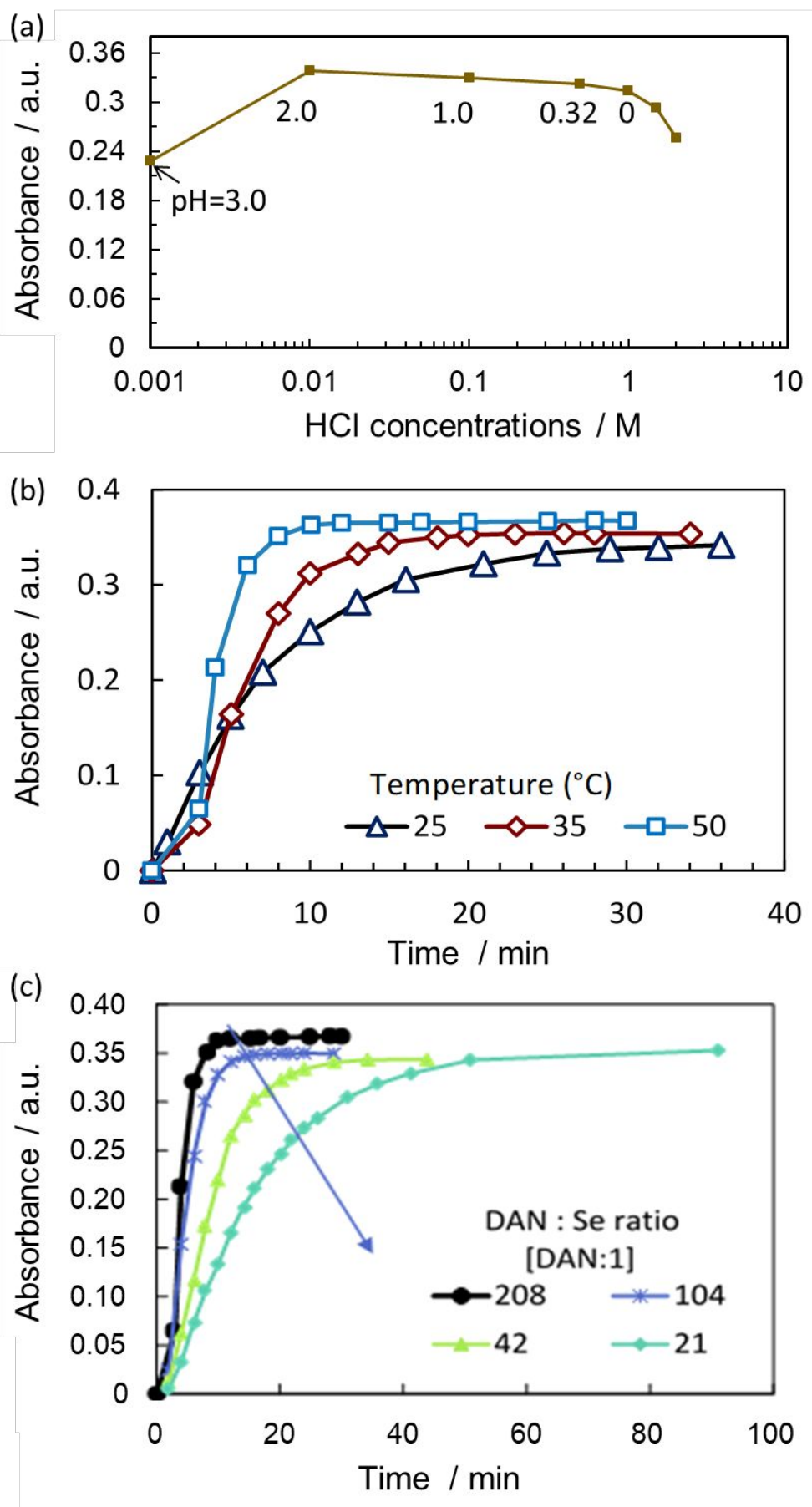

Figure S4-S3. (a) A pH dependence of absorbance at $378 \mathrm{~nm}$ of BPS in aqueous solutions prepared by varying the $\mathrm{HCl}$ concentrations of $0.001-2.0 \mathrm{M} \mathrm{HCl}$ at $50^{\circ} \mathrm{C}$, (b) Temperature dependence of absorbance of BPS against the elapse of time. (c) Time course of the absorbance of BPS against [DAN]/[Se(IV)] concentration ratios. 

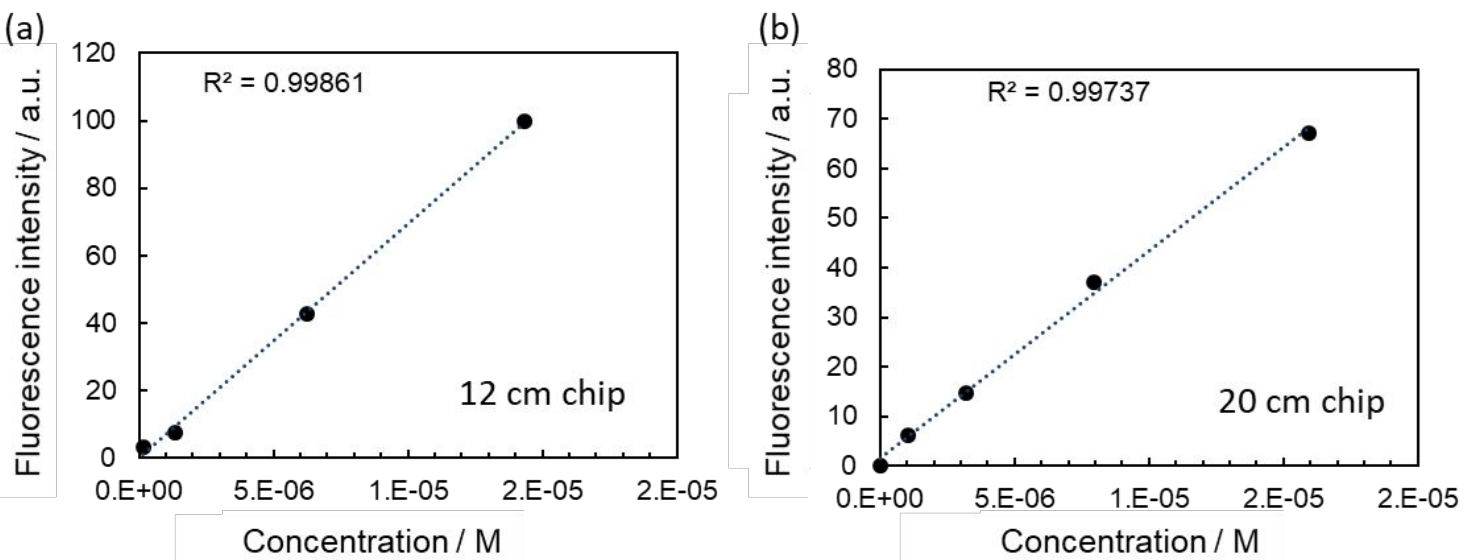

Figure S5-S4. A calibration curve of the fluorescence intensities by using online fluorescence microscopic detection vs. BPS concentrations in (a) $12 \mathrm{~cm}$ and (b) $20 \mathrm{~cm}$ microchips. 